\title{
Root-knot nematode infestations in okra fields in the forest savanna transition and moist semi-deciduous forest agro-ecologies of Ghana
}

\author{
Yaw Danso ${ }^{1,2 \star}$ and Charles Kwoseh ${ }^{2}$ \\ ${ }^{1}$ Nematology Lab, CSIR-Crops Research Institute, P. O. Box 3785, Kumasi, Ghana. \\ ${ }^{2}$ Department of Crop and Soil Sciences, Faculty of Agriculture, KNUST, Ghana.
}

Accepted 18 September, 2017

\begin{abstract}
A survey study was conducted in six major okra (Abelmoschus esculentus L.) growing districts of Ghana between August and December 2014, to assess the prevalence, incidence and severity of root-knot disease in okra incited by root-knot nematodes, Meloidogyne species. Fifty four sole okra fields were purposively selected from 18 localities for the study. On an acre okra field, 25 representative plants were systematically sampled, and assessed for incidence and degree of knotting following a rating scale 0 to 10 . Seventy six percent of the okra fields assessed were found positive for root-knot nematodes infestation. Seventy eight, 67, 67, 89, 100 and 56\% root-knot nematodes infestation prevalence were recorded in the Kintampo North, Atebubu Amantin, Wenchi, Ejura Sekyedumase, Offinso North and Atwima Nwabiagya Districts, respectively. The highest infestation incidence (95\%) was recorded at Sentiatia in the Offinso North District while the lowest (22\%) was recorded at Amponsakrom in the Wenchi District. Galling indices (severity of infestation) ranged between 5 and 8 across the districts. The root-knot nematodes infestation menace in okra is becoming endemic in most prominent okra growing localities across the surveyed areas. Sustainable management strategies must be designed by crop protectionists and disseminated among okra farmers against root-knot nematodes infestation in okra.
\end{abstract}

Keywords: Abelmoschus esculentus, Galling index, incidence, Meloidogyne species infestation.

${ }^{*}$ Corresponding author. E-mail: abiacea@yahoo.co.uk.

\section{INTRODUCTION}

Root-knot nematodes infestation is primarily among the factors that cause low okra yield worldwide (Maqbool and Shahina, 2001). Presenting data on 21 genera of plant parasitic nematodes found in Ghana, root-knot nematodes were found to be the most widespread and polyphagous (Addo, 1971). Many okra growers practice monocropping system (Danso and Kwoseh, 2016) which favours rapid build-up of root-knot nematode population leading to increased infestation levels. Awareness of plant parasitic nematodes damage has received little attention in Ghana (Addo, 1971; Osei et al., 2004; Osei et al., 2013). Therefore, root-knot nematode infestation of okra is a limiting factor to sustainable okra production. A sustained periodic assessment of okra farms for root-knot nematodes infestation; prevalence, incidence and severity, is relevant in achieving cost-effective management of the menace in okra farms for sustainable production of the vegetable crop for improved livelihood.

\section{MATERIALS AND METHODS}

Okra farms were assessed in six districts; Forest Savanna Transition and Moist Semi-deciduous Forest agro-ecologies for prevalence of root-knot nematodes infestation. A total of 54 okra farms were assessed in 16 localities across the six districts (Table 1, Figure 1).

All the sampled districts experienced a bimodal rainfall regime. Sole okra farms were purposively selected for the study. Before farms' assessment, advocacy visits were made to the target 
Table 1. Description of the surveyed area.

\begin{tabular}{|c|c|c|c|c|}
\hline Agro-ecology / District & Locality & Altitude (m) & Total / range of rainfall $(\mathrm{mm})$ & Mean / range of temp. $\left({ }^{\circ} \mathrm{C}\right)$ \\
\hline \multirow{3}{*}{ Kintampo North ${ }^{2}$} & Naaba-kura & 164 & \multirow{3}{*}{$1,600(0-340)$} & \multirow{3}{*}{$27(24-31)$} \\
\hline & Gyinapintin & 171 & & \\
\hline & Babatokuma & 168 & & \\
\hline \multirow{3}{*}{ Atebubu Amantin ${ }^{2}$} & Duabone & 134 & \multirow{3}{*}{$871(0-355)$} & \multirow{3}{*}{$27(25-32)$} \\
\hline & Adom & 131 & & \\
\hline & ATSEC & 139 & & \\
\hline \multirow{3}{*}{ Wenchi $^{2}$} & Awisa & 281 & \multirow{3}{*}{$893(0-369)$} & \multirow{3}{*}{$27(24-31)$} \\
\hline & Akrobi & 213 & & \\
\hline & Amponsakrom & 245 & & \\
\hline \multirow{3}{*}{ Ejura Sekyedumase $^{3}$} & Hiawoanwu & 202 & \multirow{3}{*}{$1,236(0-366)$} & \multirow{3}{*}{$26(25-29)$} \\
\hline & Nkwanta & 183 & & \\
\hline & Teacherkrom & 189 & & \\
\hline \multirow{3}{*}{ Offinso North ${ }^{3}$} & Abaka & 374 & \multirow{3}{*}{$1,507(9.3-271)$} & \multirow{3}{*}{$27(25-29)$} \\
\hline & Apatam & 376 & & \\
\hline & Sentiantia & 349 & & \\
\hline \multirow{3}{*}{ Atwima Nwabiagya $^{3}$} & Afari & 215 & \multirow{3}{*}{$1,835(11-270)$} & \multirow{3}{*}{27 (24-29) } \\
\hline & Nerebehi & 208 & & \\
\hline & Kyereyaase & 211 & & \\
\hline
\end{tabular}

Temp. $=$ temperature, ${ }^{3}$ Moist Semi-deciduous Forest, ${ }^{2}$ Forest Savanna Transition.
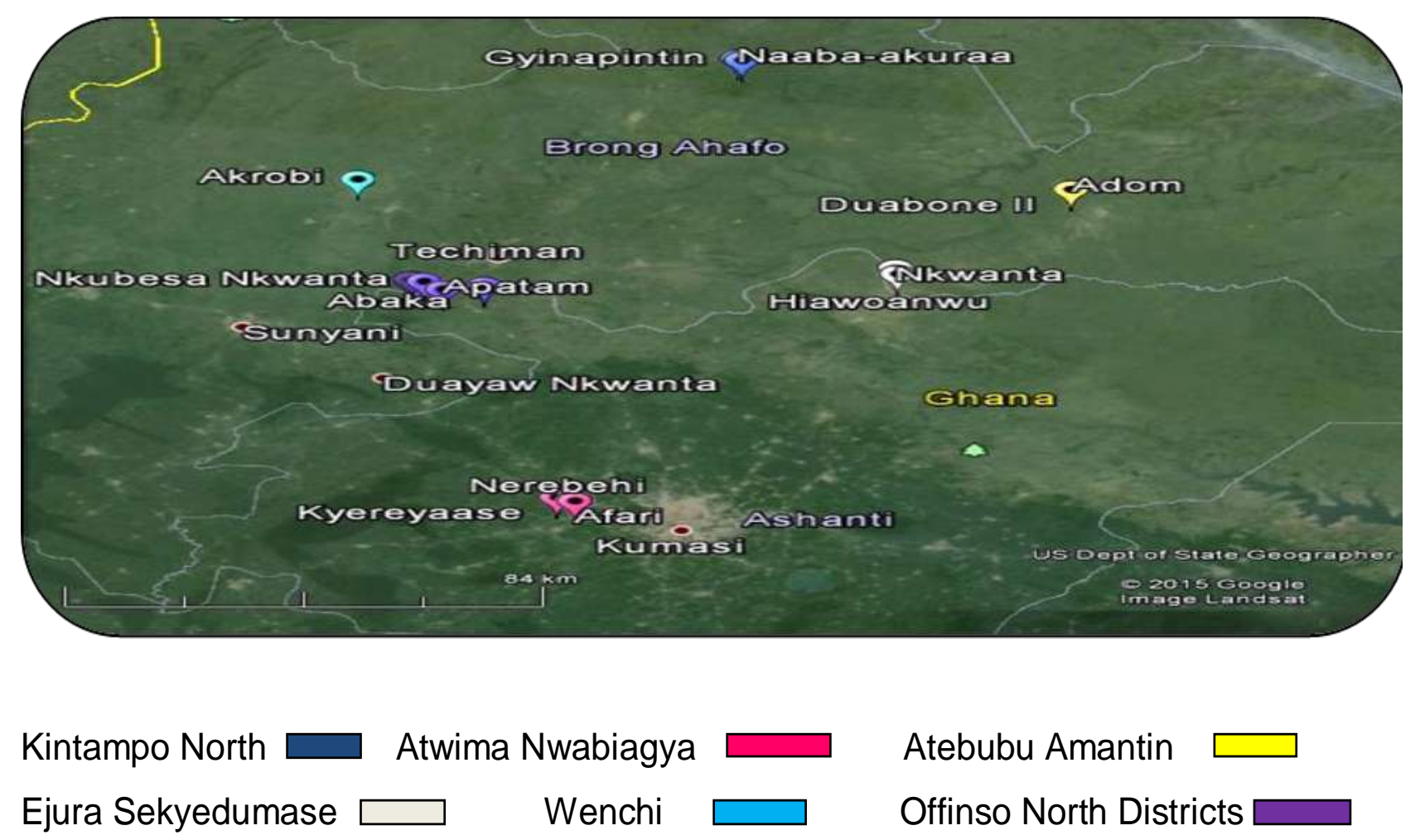

Figure 1. Map of the sampling locations in six districts of Ghana. 
localities to engage the relevant farmers on the importance of the study and to seek their permission and cooperation to assess their okra farms. For an acre of okra farm $\left(4,000 \mathrm{~m}^{2}\right), 25$ representative matured okra plants were sampled systematically. Okra farms larger than 1 acre were divided and assessed accordingly. The selected okra plants were uprooted carefully up to about $30 \mathrm{~cm}$ soil depth with the aid of a hand trowel. Soil adhering to the root system was gently removed before observation of the galls.

For root-knot nematode infestation severity, five infested okra plant roots were rated for galling indices on each okra farm using the rating scale 0 to 10 (Bridge and Page, 1980): $0=$ no knots on roots; 1 = few small knots and difficult to find; 2 = small knots only but clearly visible; $3=$ some larger knots visible; $4=$ larger knots predominate but main roots clean; $5=50 \%$ of roots affected and some main roots knotted; 6 = knotting on main roots; 7 = majority of main roots knotted; 8 = all main roots and tap root knotted; $9=$ all roots severely knotted and plant usually dying; $10=$ all roots severely knotted, no root system and plant usually dead.

Geographic coordinates were recorded for each field by using a Global Positioning System device (GARMIN, GPSMAP ${ }^{\circledR}$ 62s: www.garmin.com). Total precipitation $(\mathrm{mm})$ and annual mean air temperatures $\left({ }^{\circ} \mathrm{C}\right)$ were obtained from the nearest weather stations.

Incidence of infestation on each farm was determined (Husain et al., 2012) as:

Incidence $(\%)=\frac{\text { Number of infested plants }}{\text { Number of plants assessed }} \times 100$

Prevalence of infestation for each locality was calculated (Husain et al., 2012) as follows:

Prevalence $(\%)=\frac{\text { Okra farms with infestation symptoms }}{\text { Number of farms assessed }} \times 100$

Data collected were analysed using SPSS and presented in tables and charts.

\section{RESULTS}

Relevant agro-climatic data (total precipitation, mean annual air temperatures and altitude - height above sea level) have been presented in Table 1. District mean annual air temperatures ranged between 26 and $27^{\circ} \mathrm{C}$, while total precipitation was between 871 and $1,835 \mathrm{~mm}$ for the period between January and December, 2014. Altitude ranged between 211 and $376 \mathrm{~m}$ across the districts.

Table 2 shows prevalence of root-knot nematodes infestation in okra. Mean infestation prevalence across the districts was $76 \%$. Seventy-eight, $67,67,89$ and $56 \%$ of the okra fields assessed showed symptoms of rootknot nematodes infestation (conspicuous galling) in the Kintampo North, Atebubu Amantin, Wenchi, Ejura Sekyedumase and Atwima Nwabiagya Districts, respectively. All the $9(100 \%)$ okra fields assessed in the Offinso North District showed symptoms of root-knot nematodes infestation.

Root-knot nematode infestation incidence in okra was highest $(95 \%)$ at Sentiatia in the Offinso North District and least $(22 \%)$ at Amponsakrom in the Wenchi District (Figure 2).
All the localities across the districts recorded high okra plant galling indices $(>5.0)$ induced by root-knot nematodes (Figure 3 ). The least infestation severity score (5.0) was recorded at Hiawoanwu and Apatam in the Ejura Sekyedumase and Offinso North Districts (Figure 4).

\section{DISCUSSION}

There was high prevalence, incidence and severity of the root-knot nematodes infestation in okra across the districts sampled. This is because okra plant is susceptible to root-knot nematodes parasitism. This may contribute to higher incidence of infestation and severity under favourable climatic conditions (Shahid et al., 2007). High incidence of infestation recorded across the localities could be as a result of continuous cropping of susceptible crops without any sustainable management interventions (Khan et al., 2005). Farmers are rarely able to undertake rotational cropping as a management intervention because root-knot nematode species have wide host ranges. This makes the selection of rotational crops difficult. Osei et al. (2013) reported that farmers' ignorance about plant parasitic nematode infestation problems in Ghana presents a major challenge in management efforts to reduce root-knot nematode population levels on crop farms. This allows the parasites to thrive in infested farm lands season after season.

The two agro-ecologies studied fall within the warm tropical climate. Tropical climatic environment is suitable for tropical root-knot nematode species to thrive in the presence of suitable host plants. According to Van-Gundy (1985), the commonest species of root-knot nematodes (Meloidogyne incognita, M. javanica and $M$. arenaria) are often adapted to the tropical climates. This study was carried out under mean air temperatures ranging between 26 and $27^{\circ} \mathrm{C}$, typical of tropical climates. Survival of tropical root-knot nematode species reduced at extreme temperatures $\left(<5\right.$ and $>35^{\circ} \mathrm{C}$ ) (Taylor et al., 1982). Osei et al. (2013) reported of relative abundance of $M$. incognita at Akomadan in the Offinso North District of Ghana. Annual rainfall recordings across the districts ranged between 871 and $1,835 \mathrm{~mm}$ during this study. Tropical root-knot nematodes were more numerous in areas receiving $\geq 1,500 \mathrm{~mm}$ annual rainfall (Taylor et al., 1982). The low infestation prevalence recorded for the localities in the Wenchi District (Awisa, Akrobi and Amponsakrom) (Figure 2) might be partly due to the lower total rainfall $(893 \mathrm{~mm})$ recorded for the district during the study period.

\section{Conclusion}

Okra is severely parasitized by root-knot nematodes. It is evident that the infestation is becoming endemic in most prominent okra growing localities. It is important to 
Table 2. Prevalence of root-knot nematodes infestation in okra fields in 6 districts of Ghana.

\begin{tabular}{|c|c|c|c|c|}
\hline District & Locality & Infested farms & Non-infested farms & Infestation prevalence (\%) \\
\hline \multirow{4}{*}{ Kintampo North ${ }^{1}$} & Naaba akuraa & 2 & 1 & 67 \\
\hline & Gyinapintin & 2 & 1 & 67 \\
\hline & Babatokuma & 3 & 0 & 100 \\
\hline & Davaivintra & $\mathrm{u}$ & 0 & $78^{*}$ \\
\hline \multirow{3}{*}{ Atebubu Amantin ${ }^{1}$} & Duabone & 3 & 0 & 100 \\
\hline & Adom & 2 & 1 & 67 \\
\hline & ATSEC & 1 & 2 & $\begin{array}{l}33 \\
67\end{array}$ \\
\hline \multirow{4}{*}{ Wenchi ${ }^{1}$} & Awisa & 3 & 0 & 100 \\
\hline & Akrobi & 2 & 1 & 67 \\
\hline & Amponsakrom & 1 & 2 & 33 \\
\hline & & & & 67 \\
\hline \multirow{4}{*}{ Ejura Sekyedumase ${ }^{2}$} & Nkwanta & 3 & 0 & 100 \\
\hline & Hiawoanwu & 3 & 0 & 100 \\
\hline & Teacherkrom & 2 & 1 & 67 \\
\hline & & & & 89 \\
\hline \multirow{4}{*}{ Offinso North ${ }^{2}$} & Abaka & 3 & 0 & 100 \\
\hline & Apatam & 3 & 0 & 100 \\
\hline & Sentiantia & 3 & 0 & 100 \\
\hline & & & & 100 \\
\hline \multirow{4}{*}{ Atwima Nwabiagya $^{2}$} & Afari & 2 & 1 & 67 \\
\hline & Nerebehi & 1 & 2 & 33 \\
\hline & Kyereyaase & 2 & 1 & 67 \\
\hline & & & & 56 \\
\hline
\end{tabular}

* Mean \% prevalence, ${ }^{2}$ Moist Semi-deciduous Forest, ${ }^{1}$ Forest Savanna Transition.

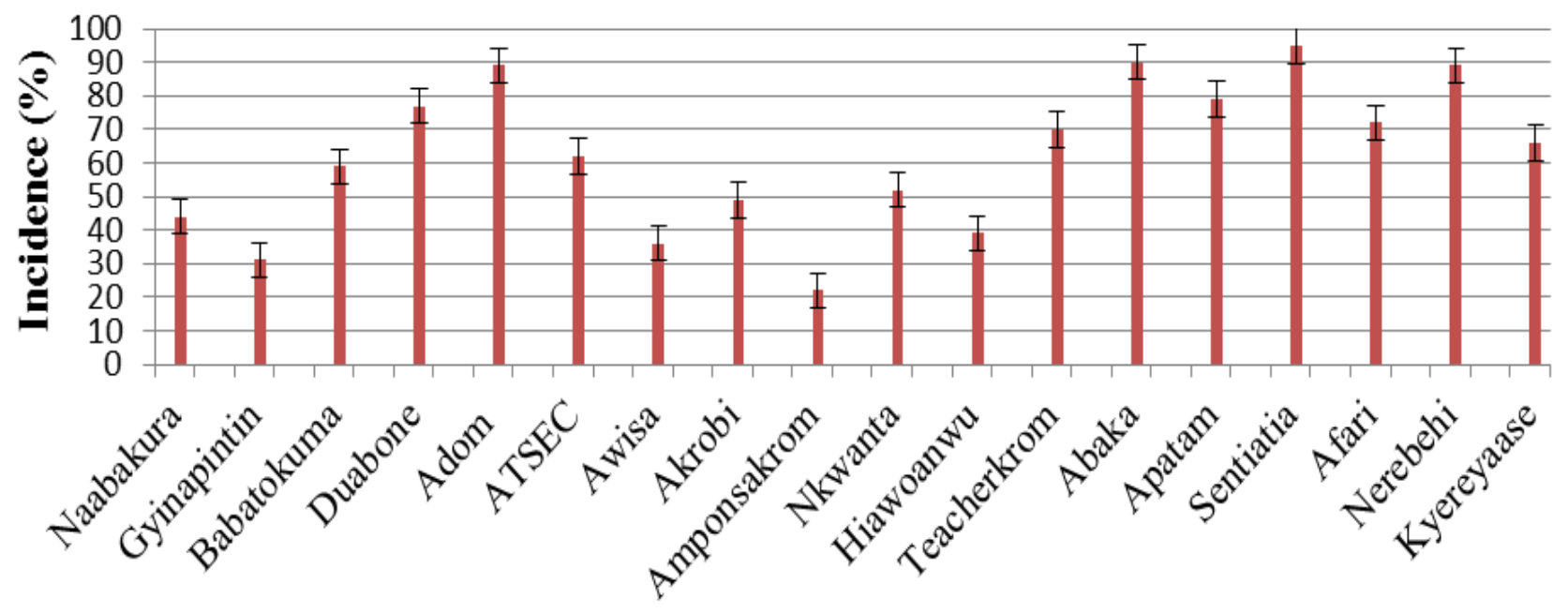

\section{Localities}

Figure 2. Incidence of root-knot nematodes infestation of okra in 18 localities. $n=3$ okra farms per locality. 


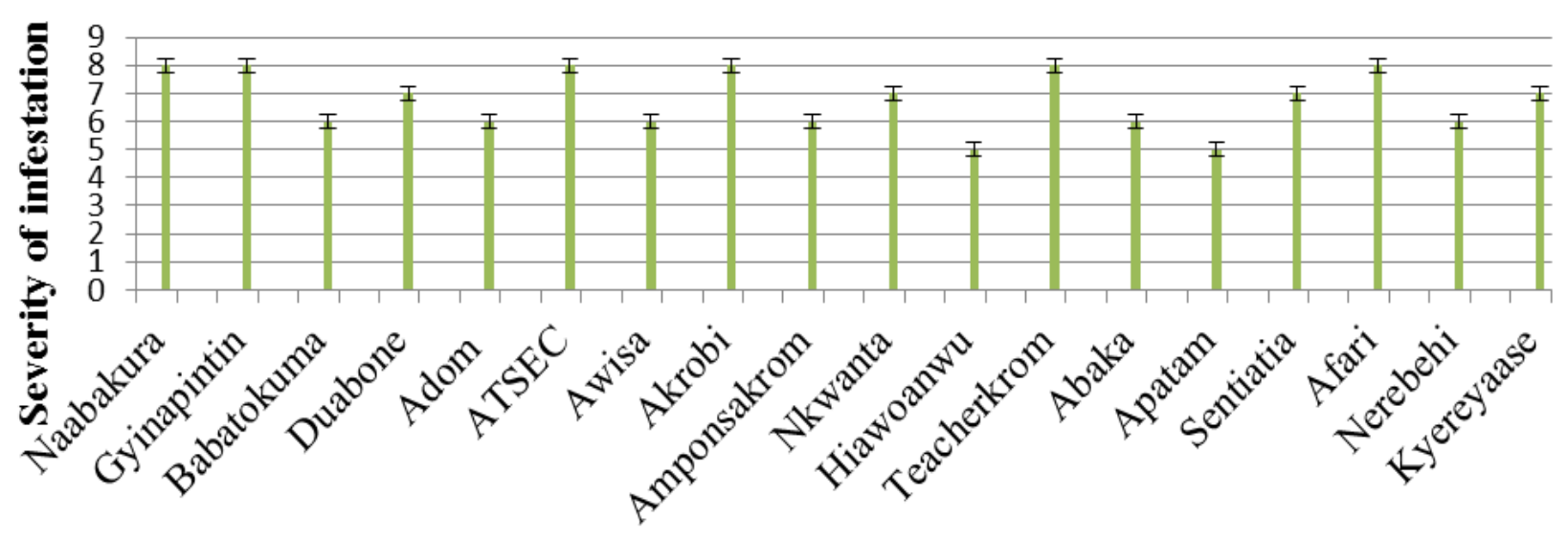

\section{Localities}

Figure 3. Galling indices ( 0 to 10 ) of root-knot nematodes infestation in okra in 18 localities across 6 districts, $n=3$ okra farms per locality.
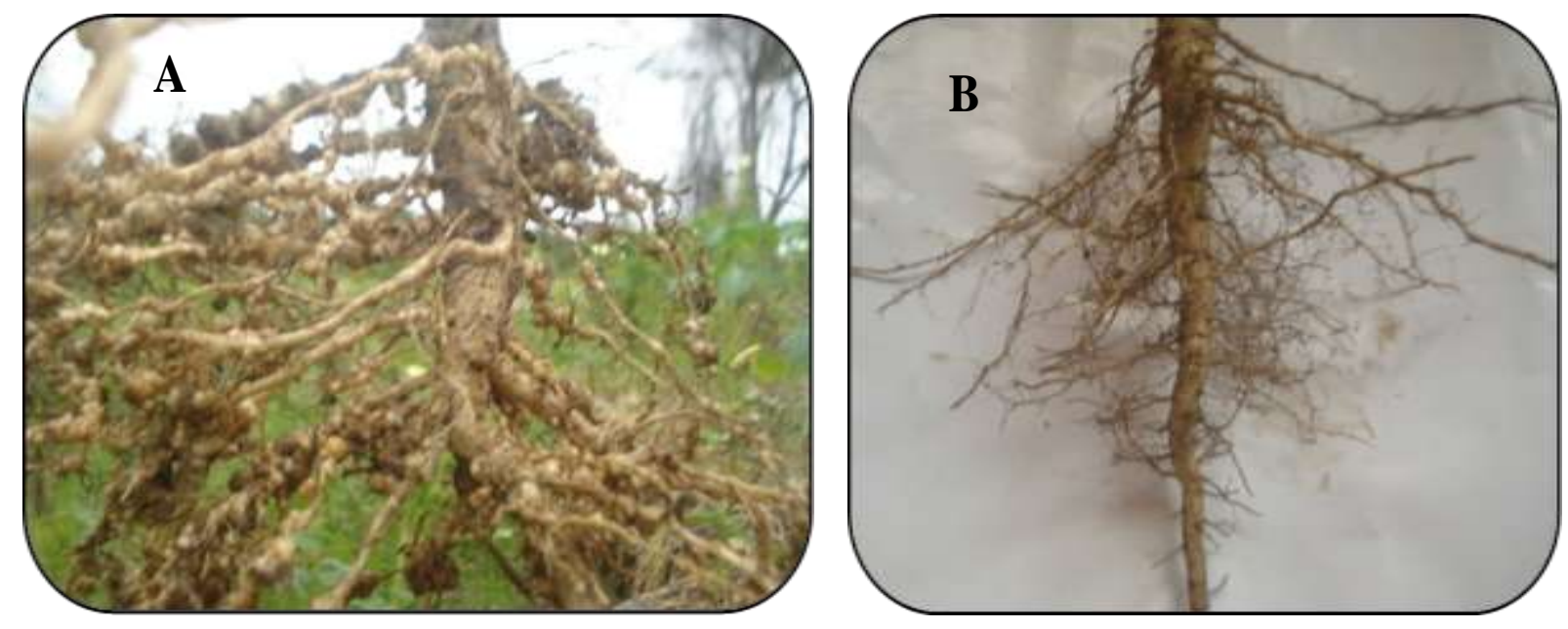

Figure 4. (A) Okra plant root system disfigured by root-knot nematodes infestation on a farmer's field, (B) Uninfested okra plant with fine feeder roots without galls.

develop sustainable management strategies for adoption to combat the menace.

\section{ACKNOWLEDGEMENTS}

Authors are grateful to the World Bank for sponsoring this work through the West African Agricultural Productivity Programme (WAAPP, Ghana). The work was carried out in close collaboration with personnel of the Ministry of Food and Agriculture (MoFA), Ghana.

\section{REFERENCES}

Addo PG, 1971. The distribution and economic importance of plant parasitic nematodes in Ghana. Ghana J Agric Sci, 4: 21-32.

Bridge J, Page SLJ, 1980. Estimation of root-knot nematode infestation levels on roots using a rating chart. Trop Pest Manag, 26(3): 296 298.

Danso Y, Kwoseh C, 2016. Some okra production decisions and farmers' awareness of Meloidogyne spp. infection in two agroecologies of Ghana. Am J Exper Agric, 11(5): 1-6.

Husain MA, Mukthar T, Kayani MZ, Aslam MN, Haque MI, 2012. A survey of okra (Abelmoschus esculentus) in Punjab province of Pakistan for the determination of prevalence, incidence and severity of root-knot disease caused by Meloidogyne spp. Pak J Bot, 44(6): 187-194.

Khan HU, Mukhtar T, Ahmad R, 2005. Geographical distribution of rootknot nematodes (Meloidogyne spp.) in the Punjab province of Pakistan. Pak J Nematol, 23(1): 133-140.

Maqbool MA, Shahina F, 2001. Systematics and distribution: biodiversity of nematode fauna in Pakistan. National Nematological Research Centre, University of Karachi, 75270, Pakistan, 179.

Osei K, Awuah RT, Tabil MA, Asante JS, 2004. Prevalence and farmers' perceptions of plant parasitic nematodes in yam rhizosphere soils from yam producing areas of Ghana. Agric Food Sci J Ghana, 3: 217-225.

Osei K, Mintah P, Dzomeku, BM, Braimah H, Adomako J, Mochiah MB, 
Asiedu E, Darkey S, Danso Y, 2013. Nematode pests of plantain: A case study of Ashanti and Brong Ahafo Regions of Ghana. J Soil Sci Environ Manag, 4(1): 6-10.

Shahid M, Ahmad AU, Khan AU, Mahmood A, 2007. Geographical distribution and infestation of plant parasitic nematodes on vegetables and fruits in the Punjab province of Pakistan. Pak $\mathrm{J}$ Nematol, 25(1): 59-67.

Taylor AL, Sasser JN, Nelson LA, 1982. Relationship of climate and soil characteristics to geographical distribution of Meloidogyne in agricultural soils. North Carolina State University and USAID, Raleigh.

Van-Gundy SD, 1985. Ecology of Meloidogyne spp. - Emphasis on environmental factors affecting survival and pathogenicity. In: Sasser JN, Carter CC (Eds.). An advanced treatise on Meloidogyne. Vol. I. Biology and Control. N. C. State Univ. Graphics, Raleigh, North Carolina, 177-182.
Citation: Danso Y, Kwoseh C, 2017. Root-knot nematode infestations in okra fields in the forest-savanna transition and moist semideciduous forest agro-ecologies of Ghana. Microbiol Res Int, 5(3): 37 42. 